
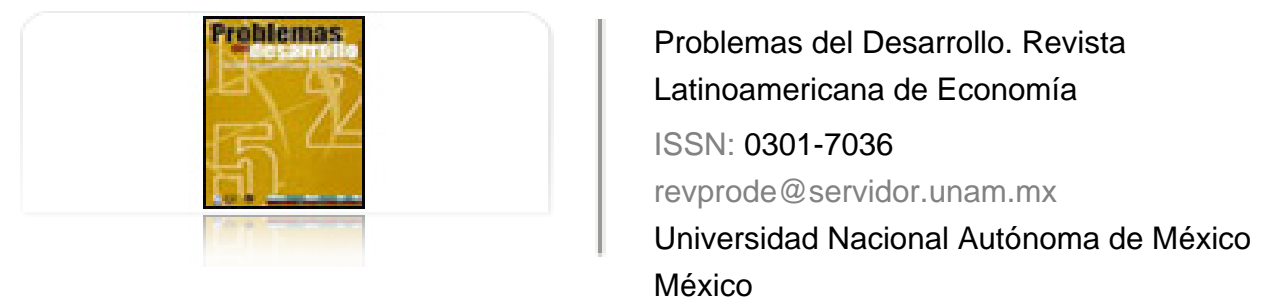

Tovar García, Edgar

CONSECUENCIAS DE LA GLOBALIZACIÓN FINANCIERA SOBRE LA EFICIENCIA DEL SISTEMA

FINANCIERO

Problemas del Desarrollo. Revista Latinoamericana de Economía, vol. 42, núm. 167, octubrediciembre, 2011, pp. 147-174

Universidad Nacional Autónoma de México

Distrito Federal, México

Disponible en: http://www.redalyc.org/articulo.oa?id=11820101007

Cómo citar el artículo

- Número completo

- Más información del artículo

Página de la revista en redalyc.org

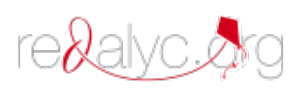

Sistema de Información Científica

Red de Revistas Científicas de América Latina, el Caribe, España y Portugal Proyecto académico sin fines de lucro, desarrollado bajo la iniciativa de acceso abierto 
Revista Problemas del Desarrollo, 167 (42), octubre-diciembre 2011

\title{
CONSECUENCIAS DE LA GLOBALIZACIÓN FINANCIERA SOBRE LA EFICIENCIA DEL SISTEMA FINANCIERO
}

\author{
Edgar Tovar García*
}

Fecha de recepción: 11 de enero de 2011. Fecha de aceptación: 14 de junio de 2011.

\section{RESUMEN}

El artículo aborda teórica y empíricamente el nexo globalización financiera-eficiencia del sistema financiero. Presenta una prueba empírica novedosa, en tanto que utiliza nuevos indicadores de globalización financiera y del desempeño de las funciones básicas del sistema financiero. Se emplea un modelo dinámico con datos de panel, cuyos principales resultados sugieren que la globalización financiera favorece la profundización financiera. Respecto a la eficiencia con que los sistemas financieros domésticos desempeñan sus funciones básicas, solamente se puede argumentar que la globalización financiera mejora el control corporativo y facilita la movilización y reunión del ahorro, pero acompañado de volatilidad en el consumo (empeora la administración y diversificación del riesgo) y mayor concentración bancaria (empeora la información sobre las condiciones de los mercados financieros).

Palabras clave: globalización financiera, eficiencia del sistema financiero, panel de datos dinámico y estimador general de momentos.

\section{CONSEQUENCES OF FINANCIAL GLOBALIZATION IN FINANCIAL SYSTEM EFFICIENCY}

\begin{abstract}
This article deals theoretically and empirically with the financial globalization / financial system efficiency nexus. It presents a novel empirical test, while applying new indicators for financial globalization and the performance of the basic functions of the financial system. A dynamic model is employed with panel data, the main results of which suggest that financial globalization favors financial deepening. Regarding the efficiency in which domestic financial systems perform their basic functions, it can only be argued that financial globalization improves corporate control and facilitates the mobilization and amassing of saving, but that this is accompanied by volatility in consumption (it worsens the administration and diversification of risk) and greater bank concentration (it worsens the information on financial markets conditions).

Key words: Financial globalization, efficiency of the financial system, Dynamic Panel Data and Generalized Method of Moments Estimation.

* Investigador de la Universidad Nacional de Investigación "Alta Escuela de Economía”, Moscú, Rusia. Correo electrónico: beno09@yahoo.com

El autor agradece a DGAPA y a la Facultad de Economía de la UNAM, por el apoyo para la investigación durante su estancia posdoctoral, así como los valiosos comentarios de Noemí Levy Orlik, y la labor como asistente de investigación de Evgeniya Vadimovna Guseva.
\end{abstract}


Edgar Tovar García

\section{CONSÉQUENCES DE LA MONDIALISATION FINANCIÈRE SUR L'EFFICIENCE DU SYSTÈME FINANCIER \\ Résumé}

Cet article aborde de manière théorique et empirique le lien entre la mondialisation financière et l'efficience du système financier. Il présente une preuve empirique innovante, dans la mesure où on y a recours à de nouveaux indicateurs de la mondialisation financière et de l'exercice par le système financier de ses fonctions élémentaires. Il est employé un modèle dynamique avec données de panel, dont les principaux résultats suggèrent que la mondialisation financière favorise l'approfondissement financier. En ce qui concerne l'efficience avec laquelle les systèmes financiers domestiques exercent leurs fonctions élémentaires, on ne peut qu'argumenter que la mondialisation financière améliore le contrôle corporatif et facilite la mobilisation et la réunion d'épargne, mais s'accompagne de volatilité dans la consommation (elle empire la gestion et la diversification du risque) et d'une majeure concentration bancaire (elle empire l'information sur les conditions des marchés financiers).

Mots clés : mondialisation financière, efficience du système financier, panel de données dynamique et Évaluateur général de moments.

\section{CONSEQÜÊNCIAS DA GLOBALIZAÇÃO FINANCEIRA SOBRE A EFICIÊNCIA DO SISTEMA FINANCEIRO \\ Resumo}

O artigo aborda teórica e empiricamente o nexo globalização financeira-eficiência do sistema financeiro. Apresenta-se uma nova prova empírica, ao utilizar novos indicadores da globalizaçáo financeira e do desempenho das funções básicas do sistema financeiro. Emprega-se um modelo dinâmico com dados de panel, cujos principais resultados sugerem que a globalização financeira favorece o aprofundamento financeiro. No que diz respeito à eficiência com a qual os sistemas financeiros domésticos desempenham suas funções básicas, somente se pode argumentar que a globalização financeira melhora o controle corporativo e facilita a mobilização e reunião da poupança, mas acompanhado da volatilidade no consumo (piora a administração e diversificaçáo do risco) e maior concentraçáo bancaria (piora a informação sobre as condiçóes doe mercados financeiros).

Palavras-chave: Globalização financeira, eficiência do sistema financeiro, panel de dados dinâmico e Estimador Geral de Momentos.

後果對金融體系的效率的金融全球化。

摘要

文章討論了理論和實證金融全球化，金融體系效率的關係。它提出了 新的經驗證據, 同時利用金融全球化和金融體系的基本功能性能的新 指標。它採用了與面板數據的動態模型, 主要研究結果表明, 金融全 球化促進了金融深化。關於效率的國內金融系統發揮其基本功能只能 認為, 金融全球化有利於改善公司治理, 調動和儲蓄的集合, 但在消 費波動（更糟糕的管理和分散風險伴隨著）和更大的銀行濃度（惡化 的金融市場狀況的信息)

關鍵詞：金融全球化，金融系統和動態數據小組的時刻總效益估算 


\section{INTRODUCCIÓN}

Levine (2005) y Ang (2008) resumen las aportaciones teóricas y empíricas que argumentan que el sistema financiero es un factor clave para alcanzar mayores tasas de crecimiento y desarrollo económico. En consecuencia, se han generado varias líneas de investigación para conocer los determinantes de la eficiencia con la que cada sistema se desempeńa, entre ellos, la política macroeconómica, la inflación, el marco institucional, los factores geográficos, la apertura comercial y financiera.

A partir de los años ochenta las nuevas tecnologías favorecieron un proceso continuo de interdependencia financiera entre países, le acompañó una política de apertura financiera, y los flujos internacionales de capital se incrementaron notablemente, en particular, la literatura sostiene que después del año 1987 la mayor parte de los países liberaron su cuenta de capital, e inició el periodo de mayor esplendor de la globalización financiera.

En este contexto, la pregunta que aborda este artículo es si la globalización financiera tiene efectos positivos sobre la eficiencia con la que los sistemas financieros domésticos desempeñan sus funciones básicas. A pesar de las crisis financieras, parte importante de la literatura económica argumenta teórica y empíricamente que la globalización favorece al sistema financiero doméstico, porque reduce el poder de grupos de interés, permite la adecuación del marco institucional, favorece que las mejores prácticas e innovaciones financieras se extiendan por todo el globo, y en general, porque lo anterior permite que el sistema financiero desempeñe de mejor manera sus funciones básicas.

Además de esta introducción el artículo se compone de cuatro secciones más. En la segunda, se aborda brevemente la relación teórica entre globalización financiera y las funciones básicas que debe desempeñar el sistema financiero, así como los principales resultados de estudios empíricos previos. En la tercera, se presenta la estrategia metodológica y el modelo econométrico (datos de panel dinámico). La cuarta sección presenta los principales resultados y, finalmente se cierra con una sección de conclusiones.

\section{GLOBALIZACIÓN FINANCIERA Y FUNCIONES BÁSICAS DEL SISTEMA FINANCIERO}

Obstfeld (1998: 10) señala que "la teoría económica no deja lugar a dudas acerca de las ventajas potenciales del comercio financiero global”. Por medio de modelos intertemporales borrowing/lending se sustenta teóricamente que la 
movilidad internacional de los capitales facilita la mejor aplicación de los recursos a escala mundial y una mejor administración y diversificación del riesgo. Así, el ahorro de las naciones desarrolladas espera obtener mayores rendimientos que los que cabría esperar en los mercados de origen, a la vez que las naciones subdesarrolladas suplen sus carencias de capital y se encaminan por la senda del crecimiento y desarrollo. Particularmente, "un sistema financiero abierto, en el largo plazo, será más competitivo, transparente y eficiente que uno cerrado" (Obstfeld, 2008: 2).

La heterodoxia reconoce que en un mundo con imperfecciones de mercado, particularmente con asimetrías de información, altos costos de transacción y en donde el marco institucional no genera los incentivos adecuados (propio de las naciones en vías de desarrollo), el acercamiento a la globalización financiera ${ }^{1}$ puede originar crisis, inestabilidad y pérdidas, que normalmente se reflejan en los abruptos movimientos del tipo de cambio y efectos dańinos en la estructura económica y los precios, generando inflación y baja en los salarios. ${ }^{2}$

Sin embargo, la idea de que el sistema financiero favorece al crecimiento y desarrollo económico deriva en que las transacciones financieras internacionales deben tener el mismo efecto positivo. Empero, Prasad, Rajan y Subramanian (2007) encuentran que los países no industrializados que han confiado en el capital exterior no han crecido más rápido que aquellos que no lo hicieron. Además, la inestabilidad financiera ha caracterizado a la globalización actual; Lindgren, García y Saal (1996) señalan que en el último cuarto de siglo se presentó una cifra récord de crisis financieras, entre 80 y 100, y en 2007-2008 se presentó la más grande crisis financiera global.

Es obvio que las crisis financieras y su fácil contagio, son las principales señales de alerta en contra de la globalización financiera, pero la investigación económica no tiene muchos puntos de acuerdo con esa relación.

Bailliu (2000), Eichengreen y Leblang (2003) y Bekaert, et al (2005) enuncian que el impacto de la globalización financiera será positivo para el crecimiento cuando el sistema financiero doméstico se encuentre bien desarrollado

1 Por globalización financiera se entiende el proceso de interdependencia financiera entre países, que se refleja básicamente en los flujos internacionales de capital y que se acompaña de una política de apertura financiera. La definición está basada en Fisher (2003).

2 Para conocer las críticas sobre los beneficios de la globalización financiera bajo el enfoque de las asimetrías de información véase el trabajo de Stiglitz (2000) y desde el enfoque neoinstitucional consúltese el trabajo de Arestis, Nissanke y Stein (2005). La crítica de los poskeynesianos, horizontalistas y circuitistas puede revisarse en Levy (2009). 
y regulado, es decir, con un marco institucional de alta calidad. Bajo dichas condiciones la localización del capital será eficiente y la incidencia de las crisis financieras será menor.

El sistema financiero se compone de organizaciones (bancos, banca central y otros intermediarios financieros), del propio mercado financiero, y de un marco institucional (instituciones formales e informales; leyes, reglas, reglamentos, costumbres, cultura, etcétera). La eficiencia con la que cada sistema financiero cumple con sus funciones marca su grado de desarrollo financiero. ${ }^{3}$ Esto ocurre cuando el mercado, las instituciones y las organizaciones del sistema aminoran, entre otros, los costos de transacción, de hacer cumplir los contratos, y de información, con la correspondiente mejora en la provisión de las funciones básicas del sistema financiero.

Siguiendo la clasificación de Levine (1997 y 2005), las funciones del sistema financiero son: 1) Producir información sobre las posibilidades de inversión y asignación del capital, 2) Monitorear las inversiones y ejercer un gobierno adecuado en la empresa, es decir, control corporativo (corporate governance) tras recibir el financiamiento, 3) Facilitar la administración y diversificación del riesgo, 4) Movilizar y reunir ahorros, y 5) Facilitar el intercambio de bienes y servicios.

Ahora bien, en el mundo existen sistemas financieros más desarrollados que otros, es decir, existen sistemas financieros que desempeñan las funciones básicas de manera más eficiente que otros, y gracias a la globalización financiera es factible importar un sistema financiero desarrollado, a través de un proceso de catching up generado por los flujos internacionales de capital y los procesos de interdependencia financiera.

Rajan y Zingales (2003) sostienen la hipótesis de que los sistemas financieros no se desarrollan porque al interior de los países existen grupos de interés (incumbents) que no permiten el proceso de desarrollo financiero, para así conservar su posición de poder y beneficios. Empero, la apertura financiera (y comercial) debilita a estos grupos de poder, porque los agentes externos presionan al sistema financiero nacional para que desempeñe mejor sus funciones. Además, cuando un agente financiero invierte en otro país se supone que también lleva

3 Cabe señalar que en la literatura muchas veces se utilizan como sinónimos de desarrollo financiero los términos profundización financiera o recalentamiento financiero. En este trabajo se diferencian el primero de los otros, porque profundización o recalentamiento financiero implican solamente incrementos cuantitativos de las transacciones financieras, en cambio desarrollo financiero incluye cambios cualitativos que permiten al sistema financiero mayor eficiencia en el desempeño de sus funciones básicas. 
consigo su tecnología e innovaciones financieras, mismas que terminarán por expandirse al resto de agentes financieros, si es que éstas son eficientes. La apertura financiera permite elegir la tecnología más productiva (Saint Paul, 1992 citado por De Gregorio, 1999).

Reflexionando sobre cada una de las funciones básicas que debe cumplir un sistema financiero y cuya mejora implica un mayor nivel de desarrollo financiero, es de esperar los siguientes efectos. Primero, la globalización financiera destruirá la información privilegiada de los grupos de interés (que ayuda a mantener su condición hegemónica), porque el sistema financiero tenderá a modificarse y a arrojar toda la información disponible, ante el enfrentamiento y las nuevas exigencias de los agentes económicos externos, no supeditados a dichos grupos de interés. Específicamente, la participación de agentes financieros externos genera competencia entre ellos y con los agentes locales, que les orilla a buscar y producir información más veraz y profunda de las condiciones del mercado financiero doméstico. Por el contrario, los agentes financieros externos podrían no estar interesados en la competencia, sino en la colusión y cooperación con los grupos de interés locales, para perpetuar e incrementar su poder y favorecer estructuras de mercado más cercanas al oligopolio o monopolio, donde siempre obtendrían información exclusiva.

Segundo, con la globalización financiera es factible que las mejores prácticas y técnicas de supervisión financiera se extiendan por el globo, de tal suerte que se mejore el control corporativo. Morck y Steier (2005) señalan que, a diferencia de Estados Unidos, la mayor parte de las naciones capitalistas están formadas con corporaciones que pertenecen a las familias más ricas y con una organización piramidal, y por lo tanto, el control corporativo, es decir, la decisión de asignación de los capitales, responde a estos grupos de interés y sus arreglos con el Estado. El arribo de agentes económicos externos confrontará las malas decisiones de los grupos de interés en la asignación de los capitales, mejorará el control corporativo y el desempeño de los administradores (Levine, 2002). Por el contrario, Shleifer y Vishny (1986) argumentan que la liberalización del mercado bursátil puede debilitar el control corporativo, porque reduce los incentivos de los tenedores de títulos, bajo el auspicio de mayor liquidez, a supervisar a los prestatarios y administradores.

Tercero, la globalización financiera favorece la diversificación del riesgo; esto es muy obvio a escala mundial, porque los agentes nacionales y externos pueden participar en muchos mercados financieros y compartir riesgos con muchos otros agentes. Así, en la época de auge un país puede prestar al extranjero, y en la recesión puede pedir prestado, lo cual ayuda a mitigar los impactos hacia arriba y abajo sobre el nivel de ingreso, y en consecuencia, también sobre el consumo y la 
inversión. Obstfeld (1994) señala que la diversificación internacional de los riesgos permite a la economía mundial trasladarse de un portafolio con bajo riesgo y bajo rendimiento a uno de más alto riesgo y alto rendimiento, así la integración financiera internacional permite que cada país tenga un portafolio globalmente diversificado. Asimismo, los contratos financieros que favorecen la diversificación del riesgo se difundirán en aquellas naciones donde no existen, como resultado de la búsqueda de estas opciones por parte de los agentes financieros externos. Por el contrario, si existe un mercado importante con preferencia por los activos domésticos de bienes duraderos no comerciables y altos costos de transacción asociados con el comercio internacional de bienes y activos, podrían reducirse considerablemente los incentivos para la diversificación internacional del riesgo. Además, los mercados financieros internacionales son incompletos, el riesgo de tipo de cambio y de expropiación son relevantes y no es posible adquirir seguros para todas las posibles contingencias futuras (Kose, Prasad y Terrones, 2007).

Cuarto, la opción de que los capitales fluyan libremente por el globo favorece la movilización y reunión de los ahorros a escala global. La posibilidad de llevar el ahorro doméstico al exterior en búsqueda de mejores rendimientos favorece que al interior de cada país los agentes financieros trabajen de manera más eficiente en la reunión y movilización del ahorro interno. Asimismo, se supone que el ahorro externo no sustituye al ahorro interno. Por el contrario, si la liberalización financiera brinda mejor protección contra la incertidumbre, podría de hecho disminuir las necesidades de ahorrar para el futuro y se podría tener un mejor mercado bursátil sin un incremento en el ahorro (Devereux y Smith, 1994, citado por Naceur, Ghazouani y Omran, 2008).

Finalmente, la globalización financiera aminora los costos de transacción internacionales y por tanto favorece el contacto entre el sector financiero y el sector real de la economía internacional.

\section{Análisis de la Evidencia Empírica Previa}

El nexo globalización financiera-eficiencia del sistema financiero (aunque, muchas veces en términos prácticos se trata solamente de profundización financiera) ha sido abordado principalmente en estudios empíricos, los más destacados se deben a Levine y Zervos (1998), De Gregorio (1999), Klein y Oliver (2001), Chinn e Ito (2002 y 2006), Law y Demetriades (2006), Huang W. (2006), Calderón y Kubota (2009), Law (2009) y Baltagi, Demetriades y Law (2009).

La eficiencia de los sistemas financieros domésticos ha sido aproximada en la gran mayoría de los estudios a partir de indicadores de crédito y del mercado 
bursátil; pasivos líquidos en proporción al PIB, crédito en proporción al PIB, valores comercializados (valor total) en proporción al PIB, valores comercializados en proporción al volumen de ventas, cociente entre la emisión de acciones y el PIB, etcétera.

Con respecto a la globalización financiera debe señalarse que el término es poco utilizado, seguramente para evitar la discusión de su definición en consecuencia abundan neologismos cercanos como apertura financiera, apertura de la cuenta de capital, liberalización financiera y algunos otros. El principal indicador para mediar a esta variable está relacionado con la apertura financiera o eliminación de los controles de la cuenta de capital, con base en el indicador del FMI sobre restricciones en la cuenta de capital (Annual Report on Exchange Arrangements and Exchange Restrictions). Unos pocos estudios recurren a los flujos internacionales de capital o a alguna medida de integración financiera basada en modelos de arbitraje internacional de precios.

Los modelos econométricos empleados para evaluar la relación han mejorado con el paso de los años, en parte como resultado de una mayor disponibilidad de datos. Del empleo inicial del análisis gráfico o mínimos cuadrados ordinarios (MCO) se ha evolucionado a modelos con datos de panel (DP) y estimación general de momentos (GMM).

Las variables de control utilizadas en los distintos modelos son básicamente el nivel de ingreso, la inflación y la apertura comercial. Es interesante notar que tras el trabajo de Chinn e Ito (2002) comenzaron a incluirse variables institucionales, conforme a una tendencia en la que el marco institucional tomaba relevancia como determinante del desarrollo financiero, con base en el trabajo de La Porta, López-de-Silanes, Shleifer y Vishny (1998).

La muestra de países, empleada en las distintas pruebas, también se incrementó con el paso del tiempo, aunque siempre hay reducciones importantes como resultado de la carencia de algunos datos para ciertos países y variables, sobre todo las de tipo institucional. Además, el periodo de análisis intentó extenderse hacia el pasado hasta 1960 sin éxito, porque al momento de estimar los modelos incluyendo las variables de control y las institucionales, la información sólo estaba disponible principalmente para el periodo comprendido entre 1980 y 2003-2005.

En general en el caso de las naciones desarrolladas, los resultados de las pruebas empíricas apuntan hacia un efecto positivo de la globalización financiera sobre la profundización financiera, y se supone que ello conlleva una mayor eficiencia en el desempeño de las funciones básicas del sistema financiero. En los países subdesarrollados la evidencia es mixta y predominan efectos positivos en muestras de países emergentes. Además, los resultados sugieren que cuando 
existe un buen nivel de desarrollo institucional, la globalización financiera tiene efectos favorables.

\section{ESPECIFICACIÓN EMPÍRICA}

Después de revisar las distintas técnicas econométricas en la estimación del nexo globalización financiera-eficiencia del sistema financiero, la mejor opción es emplear el método generalizado de momentos (GMM) con datos de panel dinámico en dos etapas, que usa una matriz de varianza-covarianza optimizada que corrige problemas de autocorrelación de segundo orden conforme a la propuesta de Arellano y Bond (1991). El modelo se estima en primeras diferencias y permite que rezagos de la variable dependiente entren como regresores, y provee un mejor control de la endogeneidad en todas las variables explicativas, ya que permite que las variables (incluyendo rezagos de la dependiente como regresor) ${ }^{4}$ funjan como instrumentos. Así se eliminan los efectos específicos de un país y se prevé simultaneidad. Además las variables explicativas se asumen exógenas, se introducen con un rezago y se transforman en logaritmos ${ }^{5}$ (véase ecuación 1).

$\ln D F_{i t}=\rho_{1} \ln D F_{i t-1}+\rho_{2} \ln G F_{i t-1}+\ln X_{i t-1}^{\prime} \beta+\gamma U K L O_{\mathrm{i}}+\lambda D 1_{\mathrm{i}}+u_{i t}$

donde $D F$ es la medida de eficiencia del sistema financiero, $G F$ es la medida de globalización financiera y $X$ es un grupo de variables de control: el logaritmo del PIB per cápita en dólares constantes (GDP), la tasa de inflación (INFLA) y el logaritmo de la apertura comercial (xM) calculada como la suma de exportaciones

4 Se utilizan dos rezagos de la variable dependiente como instrumentos, para mantener la sensibilidad de las observaciones de corte transversal y el número de restricciones de sobre identificación.

5 A excepción de las variables de apertura financiera (KAOPEN) e inflación (INFLA), que por su naturaleza contienen cifras negativas y no es conveniente transformarlas en logaritmos. Asimismo, cabe subrayar que las variables dicotómicas no sufren ninguna transformación.

6 Los momentos condicionales son: $E\left[u_{i t} D F_{t-k}\right]=E\left[u_{i t} X_{t-k}\right]=0 \forall k>1$, donde $X$ son las variables explicativas.

Para que la estimación sea eficiente se requiere que los residuos no presenten autocorrelación, primordialmente de segundo orden y, como se utilizan instrumentos y los momentos condicionales incrementan con el tiempo, se requiere que no haya problemas de sobreidentificación (para ello se calcula la prueba de Sargan).

El coeficiente $\rho_{2}$ representa el efecto de corto plazo, como resultado de incluir la variable dependiente rezagada como regresor; para conocer el efecto de largo plazo hay que dividirlo entre $1-\rho_{1}$. Igual ocurre con el resto de coeficientes. 


\section{Edgar Tovar García}

e importaciones como porcentaje del PIB. ${ }^{7}$ UKLO es una variable dicotómica institucional sobre el origen de la legislación del país, si éste es inglés (1) y si la legislación del país tiene otro origen; francés, escandinavo o germano $(0) .{ }^{8} \mathrm{D} 1$ es una variable dicotómica, para país desarrollado (1) y país en vías de desarrollo (0). Los indicadores se describen con mayor detalle en la sección de datos. ${ }^{9}$

La hipótesis fundamental por contrastar es que la eficiencia con la que el sistema financiero desempeńa sus funciones básicas depende positivamente del nivel de globalización financiera. También es de esperar que exista una relación positiva con las variables de control (excepto la tasa de inflación). Las variables dicotómicas sobre el origen de la legislación y el nivel de desarrollo indican si los resultados del modelo dependen de que se trate de un país desarrollado y con tradición inglesa en su legislación.

\section{Los datos}

Los datos se obtienen del Banco Mundial, World Development Indicators (WDI) 2005 y 2008, y las bases de datos asociadas con Beck, Demirgüç-Kunt y Levine

7 El logaritmo del pIB per cápita (GDP) es incluido como variable de control porque existe una amplia literatura que le atribuye favorecer la profundización financiera con una doble causalidad (Levine, 2005). La inflación es incluida porque genera fricciones en el mercado que pueden afectar la racionalización del crédito, y la actividad de las instituciones financieras disminuye (Roubini y Sala-i-Martin, 1995; Boyd, Levine, y Smith, 2001). La apertura comercial es incluida como variable de control porque los estudios empíricos encuentran una correlación positiva entre la apertura comercial y el desarrollo financiero (Do y Levchenko, 2004; Huang y Temple, 2005 y Baltagi, Demetriades y Law, 2009).

8 Otros estudios utilizan variables institucionales cuyos valores cambian muy poco en el tiempo, o simplemente utilizan un mismo valor para todo el periodo de análisis, porque los datos disponibles no permiten capturar adecuadamente los cambios institucionales (de las reglas formales e informales) en una época en que efectivamente hay modificaciones sustanciales. Dada dicha carencia de datos, en esta investigación se piensa que es mejor utilizar variables dicotómicas de origen legal, porque éstas son efectivamente invariantes en el tiempo y capturan apropiadamente el contexto institucional. La Porta et al. (1998) argumentan que el origen legal nacional, que puede ser inglés, francés, alemán o escandinavo, afecta fuertemente el contexto legal y la regulación en las transacciones financieras, y explica las diferencias entre países en cuanto a su nivel de desarrollo financiero. Por lo anterior, en el modelo [1] la variable institucional es dicotómica.

9 Cabe aclarar que a diferencia de Chinn e Ito (2002 y 2006) y otros estudios, que utilizan el valor promedio de las variables por cada cinco años, en esta investigación se prefiere la frecuencia anual, para no perder observaciones (así lo hacen Baltagi et al, 2009). 
(2009) y La Porta et al (1998). Los años de análisis son de 1988 a 2005, porque es el periodo más enfático de la globalización actual (no se obtuvo información que permita extender el análisis a años más recientes). La muestra es de 43 países, desarrollados y en vías de desarrollo, pero disminuye ligeramente conforme a la carencia de datos de algunas variables dependientes e independientes. ${ }^{10}$

\section{Indicadores de eficiencia del sistema financiero}

Levine (2005) enfatiza que uno de los principales problemas para estudiar empíricamente al desarrollo financiero es que no existen los indicadores que capturen adecuadamente lo que teóricamente éste significa, es decir, no existen medidas de la eficiencia con la que cada sistema financiero realiza sus funciones básicas. Bajo este dilema, la gran mayoría de las investigaciones empíricas utilizan medidas de crédito y del mercado bursátil, que son medidas de crecimiento del sistema financiero (profundización financiera o recalentamiento financiero), y por lo tanto, se supone que siempre que el sistema crezca también se desarrolla.

Empero, empíricamente se ha encontrado que a pesar de que un país presente altos niveles en los ratios M2/PIB o crédito/PIB esto no implica necesariamente un sistema financiero desarrollado (Ang, 2008).

Las medidas típicas de crédito y del mercado bursátil no pueden capturar satisfactoriamente la esencia del desarrollo financiero, en parte porque los países difieren en su estructura financiera, el grado de concentración de las instituciones financieras, el tamaño de las instituciones financieras y de los instrumentos financieros, la eficiencia de los intermediarios financieros, el volumen de las transacciones financieras y la calidad del marco institucional.

Esta investigación utiliza seis medidas de crecimiento financiero, tomadas del trabajo de Beck et al (2009), que difieren de las utilizadas en otras investigaciones porque las estimaciones de estos indicadores incluyen un método de deflación y corrección, en el que se ponderan el valor inicial y su promedio anual. Tres de ellas son medidas que aproximan al crédito y tamańo del sistema financiero: 1) pasivos líquidos dividido entre el PIB (LLY), 2) crédito al sector privado proporcionado por el sector bancario y otras instituciones financieras dividido entre el PIB (CPSF) y 3) depósitos en el sistema financiero dividido entre el рIв (DSF). Otras tres medidas se refieren al mercado bursátil: 1) capitalización

10 En el anexo, véase el Cuadro A para conocer los países que integran la muestra y los principales estadísticos de las variables empleadas, y en el cuadro B se presenta la matriz de correlaciones. 
Edgar Tovar García

del mercado bursátil (sTMK), 2) los valores comercializados (valor total) dividido entre el рів (sTTV), у 3) los valores comercializados en proporción a la capitalización del mercado (STTR).

Además, se utilizan otras cuatro medidas que permiten aproximar con mayor fidelidad al desarrollo financiero, ya que aproximan a cuatro de las cinco funciones básicas del sistema financiero. ${ }^{11}$

La primera de ellas es concentración bancaria (INFORMA), que consiste en la proporción que representan los activos en poder de los tres bancos más grandes en el total de activos del sector bancario. Es una medida del grado de competencia y, por la teoría económica neoclásica, sabemos que a mayor competencia le corresponden precios que reflejan más fielmente toda la información disponible. Por lo tanto este indicador permite aproximar la primera función del sistema financiero: proporcionar más y mejor información a los agentes económicos.

Siguiendo el trabajo de Y. Huang (2005) se utilizan los activos de los bancos comerciales como proporción de la suma de sus propios activos y del banco central (CONTROL), como el indicador que permite aproximar la función de control corporativo. Ya que aproxima la intermediación financiera entre ahorro e inversión y su monitoreo, y la toma de riesgo en comparación con el banco central.

La tercera función del sistema financiero, diversificar el riesgo, se aproxima con base en los estudios de Prasad et al (2003), Bekaert et al (2006) y Kose et al (2007) que relacionan la disminución de la variabilidad del consumo con una mayor diversificación internacional del riesgo. Primero se utiliza la tasa de crecimiento del consumo total (en dólares constantes) del tiempo $t$ a $t+1$ y, posteriormente, se calcula la variabilidad de la tasa de crecimiento, definida como la desviación estándar de $t$ a $t+5$ (de cada 5 años). De igual manera se hace con el PIB, y al dividir la variabilidad del consumo entre la variabilidad del pIB se obtiene un indicador: el grado de diversificación del riesgo (entre menor variabilidad haya, mayor diversificación del riesgo habrá); este indicador se denomina RIESGO. ${ }^{12}$

11 No se encontró ningún indicador adecuado para la quinta función del sistema financiero, facilitar el intercambio de bienes y servicios.

12 Se utiliza el consumo total (privado + público); consecuentemente el indicador de riesgo no decrece como resultado del incremento en la variabilidad de alguno de los componentes del consumo. En cuanto a la volatilidad de otros componentes del pIB, por ejemplo las exportaciones netas, el indicador puede disminuir como consecuencia de esa volatilidad. Sin embargo, es de esperar que el efecto sea pequeño porque el mayor componente del PIB es el consumo, y además se trata de tasas de crecimiento y no de valores absolutos. Nótese que el objetivo de dividir la variabilidad de la tasa de crecimiento del consumo entre la variabilidad de la tasa de crecimiento del PIB es simplemente ponderar la conducta del consumo. 
El cuarto indicador es el crédito bancario como proporción de los depósitos bancarios (AHORRO), que permite aproximar el grado en que los bancos permiten canalizar los ahorros de la sociedad (o de las élites que están en posibilidad de ahorrar) hacia el sector privado. En consecuencia, aproxima la cuarta función del sistema financiero: movilizar y reunir al ahorro. ${ }^{13}$

\section{Indicadores de globalización financiera}

La gran mayoría de las pruebas empíricas aproximan a la globalización financiera con base en indicadores de apertura financiera; muchas medidas han sido diseñadas para este fin y no hay duda de que es complicado encontrar una que satisfaga completamente. ${ }^{14}$ Chinn e Ito (2002) construyeron el indicador KAOPEN, ponderando las variables: existencia de tipos de cambio múltiples ( $\mathrm{k} 1)$, restricciones a las transacciones por cuenta corriente $(\mathrm{k} 2)$, restricciones a las transacciones por cuenta de capital $(\mathrm{k} 3)$ y exigencia de la declaración de beneficios de exportación (k4). Así k1, k2 y k4 actúan como ponderadores de la intensidad de los controles de capital. ${ }^{15}$ Dadas dichas características, en esta investigación se utiliza el indicador KAOPEN para aproximar el grado de apertura financiera, $y$ por tanto, de globalización financiera.

Nótese que la apertura financiera es una característica importante de la globalización financiera, pero la magnitud de los flujos internacionales de capital es el reflejo básico del proceso globalizador. Las divisas, acciones, bonos y otros

13 Es necesario advertir que los indicadores INFORMA, CONTROL y AHORRO se refieren particularmente al sector bancario, por lo que se supone que la conducta de este sector se replica en el resto del sistema financiero.

14 Para discusiones y comparaciones sobre varias medidas de apertura y liberalización financiera véase Edison y Warnock (2001), Edwards (2001), Edison et al (2002), Lane y Milesi-Ferretti (2006) y Chinn e Ito (2008). Cabe señalar que la discusión se centra en usar medidas de facto (asociadas con los hechos, por ejemplo, los flujos internacionales de capital) o de jure (asociadas con la política, por ejemplo, KaOpen de Chinn e Ito, 2002). En este artículo, en lugar de entrar en esa discusión, se buscan indicadores que aproximen de manera más acertada lo que se entiende por globalización financiera.

15 El indicador está construido con información del FMI relatada en el informe anual sobre Exchange Arrangements and Exchange Restrictions, que proporciona la información sobre el grado y la naturaleza de las restricciones contra el exterior. Cuanto mayor es el valor de KAOPEN menor es el control sobre los capitales, mayor es la libertad de actuación del mercado, y mayor el grado de apertura o liberalización financiera y, en consecuencia, mayor es el grado de globalización financiera. Para más detalles véase Chinn e Ito (2002, 2006 y 2008). 
instrumentos financieros se están moviendo alrededor del mundo a un nivel nunca antes visto. Así, para medir la globalización financiera es necesario saber qué tan grandes son esos flujos. Para ello se utiliza la variable flujos brutos de capital privado como porcentaje del PIB (FLUJO), esto es la suma de los valores absolutos de la inversión directa, en cartera y otros, tanto entradas como salidas registradas en la cuenta financiera, excluyendo cambios del activo y pasivo de las autoridades monetarias y el gobierno.

Además, la globalización financiera implica un proceso de interdependencia financiera. Si los bienes, servicios y factores de la producción pueden moverse libremente entre países, el mercado deberá equilibrar sus precios, reflejando el proceso de interdependencia económica e integración implicado por la globalización. El precio del capital es la tasa de interés y si los flujos internacionales de capital pueden moverse libremente entre países, sus tasas de interés deben converger (Obstfeld y Taylor, 2003). ${ }^{16}$

Para medir el proceso de convergencia, en este estudio se calcula la variable integración de la tasa de interés real (INTERE), que es la tasa de interés del prestamista ajustada a la inflación a través del deflactor del PIB. Estados Unidos, Canadá, Inglaterra, Italia, Francia, Japón y Alemania (el G7) son los países que más contribuyen a los flujos internacionales de capital; por ello, el promedio de su tasa de interés se utiliza como tasa de referencia. Si un país tiene una tasa de interés cercana a dicho promedio implicaría que su integración es buena y por consiguiente mayor será su grado de globalización financiera. ${ }^{17}$

\section{ANÁLISIS ECONOMÉTRICO Y RESULTADOS EMPÍRICOS}

Cabe señalar que la evidencia empírica de este estudio contribuye a la literatura de dos formas fundamentales. Primero, aborda el nexo globalización

16 McKinnon (1973) y Shaw (1973) argumentan a favor de la liberalización del sector financiero a través de la eliminación de los controles sobre la tasa de interés. Sin embargo, es bien sabido que la tasa de interés sufre la intervención de los bancos centrales, por lo que no depende totalmente de las fuerzas del mercado, aunque en el discurso pueda ser así. Si bien es cierto que la convergencia de las tasas de interés sufre de sesgos para medir la globalización financiera, no deja de ser un buen indicador de la libertad del mercado y la liberalización financiera en la era de la globalización.

17 Otros estudios han utilizado modelos de arbitraje internacional de precios para aproximar la globalización financiera; sin embargo, el indicador aquí propuesto es elegido por la sencillez de su cálculo y porque no se aleja de los resultados que proporcionan otras medidas similares. 
financiera-desarrollo financiero utilizando tres indicadores de globalización financiera; cada uno mide una parte sustancial del fenómeno en lugar de centrarse en si son medidas de facto o de jure. Segundo, además de los indicadores típicos de profundización financiera y crédito, se utilizan cuatro indicadores que permiten aproximar de mejor manera la eficiencia con la que un sistema financiero doméstico desempeña sus funciones básicas.

Los Cuadros 1, 2 y 3 resumen los principales resultados de la estimación del modelo [1], que se transformó para incluir las distintas medidas de globalización financiera. En las columnas se encuentran las variables dependientes y en las filas las explicativas. Nótese que el uso del panel dinámico se justifica plenamente, ya que las variables dependientes rezagadas, introducidas como regresores, son todas significativas al nivel de 1\%. La prueba de Sargan no manifiesta inconvenientes con los instrumentos usados; sin embargo, las pruebas de autocorrelación advierten de problemas solamente en el caso de las medidas de crédito y del mercado bursátil, por lo que los resultados con respecto a dichas variables deben considerarse con precaución. ${ }^{18}$

\section{Apertura financiera y sistema financiero doméstico}

La ecuación [2] muestra la transformación del modelo [1] cuando se usa como medida de globalización financiera a la apertura financiera (KAOPEN).

$\ln D F_{i t}=\rho_{1} \ln D F_{i t}-1+\rho_{2} \ln K A O P E N_{i t}-1+\ln X_{i t 1}{ }^{\prime} \beta+\gamma U K L O_{\mathrm{i}}+\lambda D 1_{\mathrm{i}}+u_{i t}$

El Cuadro 1 muestra los principales resultados al utilizar la apertura financiera como medida de globalización financiera. KAOPEN tiene el signo esperado y significancia estadística al nivel de $1 \%$ con las medidas de crédito y tamaño del sistema financiero LLY, CPSF y DSF. Con respecto a los indicadores del mercado bursátil presenta una relación positiva y significativa al nivel de $1 \%$ y $5 \%$ con STMK y STTR respectivamente (con STTV no hay significancia estadística).

18 Se realizaron distintas estrategias para corregir el problema de autocorrelación de segundo orden; cambios en la muestra, transformación de las variables, inclusión y exclusión de las mismas, modificaciones de la técnica de estimación, etcétera. Pero no fue posible corregir la autocorrelación. Baltagi et al (2009: 292) encuentran el mismo problema en buena parte de sus regresiones, y a igual que ellos, no se puede más que advertir al lector de la existencia de dicha dificultad. Cabe subrayar que no hay problemas en los modelos que incluyen a los indicadores de desarrollo de las funciones del sistema financiero. 
Edgar Tovar García

Con los indicadores de eficiencia de las funciones básicas del sistema financiero existe una relación positiva y significativa al nivel de $1 \%$ con las variables CONTROL, AHORRO Y RIESGO, lo que indica que la globalización financiera favorece el control corporativo, así como la movilización y reunión del ahorro, pero sin mejorar la administración y diversificación del riesgo, es decir, KAOPEN implica mayor volatilidad del consumo, cuando debería ser de acuerdo con los planteamientos de la economía neoclásica justo al revés.

Las variables de control XM, GDP e INFLA presentan coeficientes estadísticamente significativos en la mayoría de los casos, pero no siempre presentan el signo esperado. Particularmente, la apertura comercial (хм) se relaciona significativamente y con el signo contrario al esperado con los indicadores INFORMA (favorece la concentración bancaria) y AHORRO (perjudica la movilización y reunión del ahorro), pero se relaciona significativamente y con el signo esperado con la mayoría de indicadores. Ello incluye a RIESGO, por lo que al contrario de la apertura financiera, la apertura comercial sí tiene el efecto señalado por los neoclásicos.

Los parámetros de GDP (logaritmo del PIB per cápita en dólares constantes) tienen resultados sorpresivos, particularmente cuando se comparan con los coeficientes de la variable dicotómica sobre nivel de desarrollo (DI). GDP presenta relaciones significativas y negativas con los indicadores del mercado bursátil, en tanto que D I tiene coeficientes positivos. La lectura es que los incrementos relativos, dado que se utiliza el logaritmo, es decir, los cambios porcentuales del PIB per cápita perjudican al mercado bursátil, pero los países desarrollados, que ya alcanzaron niveles altos de PIB, tienen efectos positivos sobre el mercado bursátil.

Ocurre justo lo contrario en el caso de los indicadores de crédito y tamańo del sistema financiero, es decir, los coeficientes de GDP son positivos y los coeficientes de DI son negativos; en otras palabras, los cambios porcentuales del PIB per cápita favorecen el crecimiento del crédito y el tamaño del sistema financiero, pero los países desarrollados tienen efectos negativos sobre el crédito y tamańo del sistema financiero (probablemente por la mayor relevancia que éstos dan al mercado bursátil). ${ }^{19}$

La inflación presenta el signo esperado y es estadísticamente significativa en la mayoría de los casos, aunque cabe notar que los coeficientes son pequeños.

19 La función principal de GDP es de variable de control, y aunque se hicieron ajustes para evitar la doble causalidad (el indicador está rezagado un periodo y se incluyeron instrumentos automáticamente por la metodología empleada) puede ocurrir que ello esté afectando la dirección del efecto. 
La variable dicotómica institucional sobre el origen de la legislación del país presenta coeficientes estadísticamente significativos en la mayoría de los casos, pero el signo es distinto dependiendo de lo que midan las variables financieras. La legislación de origen inglés (UKLO) se encuentra relacionada negativamente con los indicadores de crédito y tamańo del sistema financiero, y al contrario, se encuentra relacionada positivamente con las medidas del mercado bursátil. Es bien sabido que los países con origen legal inglés tienden a privilegiar el mercado de títulos, ya que poseen sistemas financieros basados en ese mercado, al contrario de otras naciones (con otros orígenes legales) cuyo sistema financiero está basado en la banca.

UKLO tiene efectos positivos sobre CONTROL y AHORRO, pero también tiene efectos positivos sobre la concentración bancaria (INFORMA), y por lo tanto tiene efectos negativos sobre la información de las condiciones de los mercados financieros.

Destaca que un país desarrollado y con origen legal inglés se relaciona positiva y significativamente con el crecimiento del mercado bursátil.

\section{Flujos brutos de capital privado y sistema financiero doméstico}

Usando como indicador de globalización financiera a los flujos brutos de capital privado (FLUJO), el modelo [1] se transforma de la siguiente manera:

$\ln D F_{i t}=\rho_{1} \ln D F_{i t-1}+\rho_{2} \ln F L U J O_{i t-1}+\ln X_{i t-1}^{\prime} \beta+\gamma U K L O_{\mathrm{i}}+\lambda D 1_{\mathrm{i}}+u_{i t}$

El Cuadro 2 muestra los principales resultados. La globalización financiera (medida con la variable FLUJo) se encuentra relacionada positiva y significativamente con las medidas de crédito y tamaño financiero, al nivel de $1 \%$ con LLY, CPSF y DSF. Con respecto a los indicadores del mercado bursátil sólo hay una relación significativa y positiva al nivel de 1\% con STMK (con STTV y STTR no hay significancia estadística).

Se encuentra que los flujos internacionales de capital favorecen el control corporativo (CONTROL), pero también promueven la concentración bancaria (INFORMA), y por lo tanto, la información sobre las condiciones del mercado se empobrece; asimismo, perjudica la función de movilizar y reunir ahorro (AHORRO).

Las variables de control y dicotómicas se comportan de forma muy similar a lo encontrado en el modelo [2], cuando la globalización financiera se midió con el indicador KAOPEN. 
Edgar Tovar García

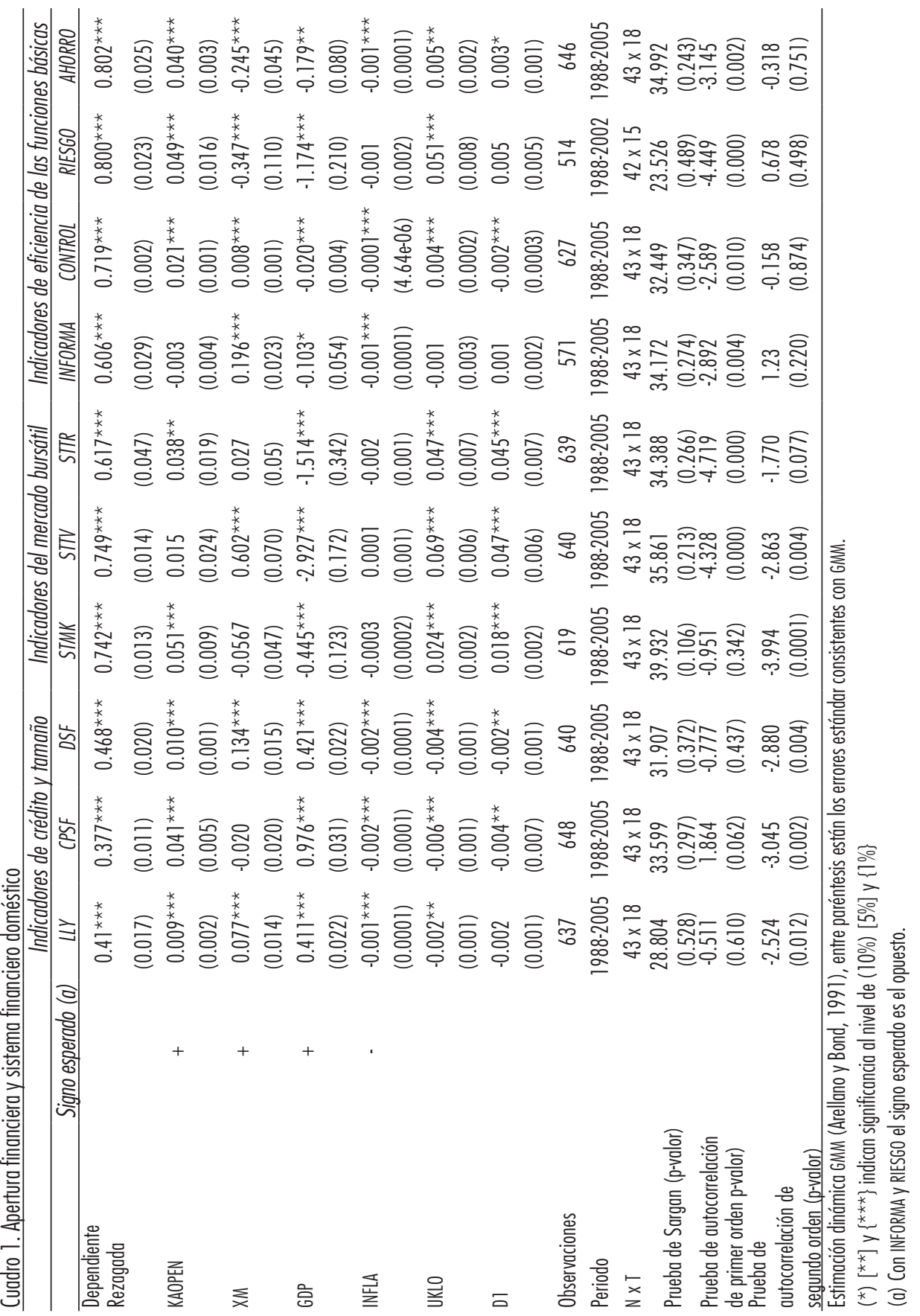


Consecuencias de la globalización financiera sobre la eficiencia del sistema financiero

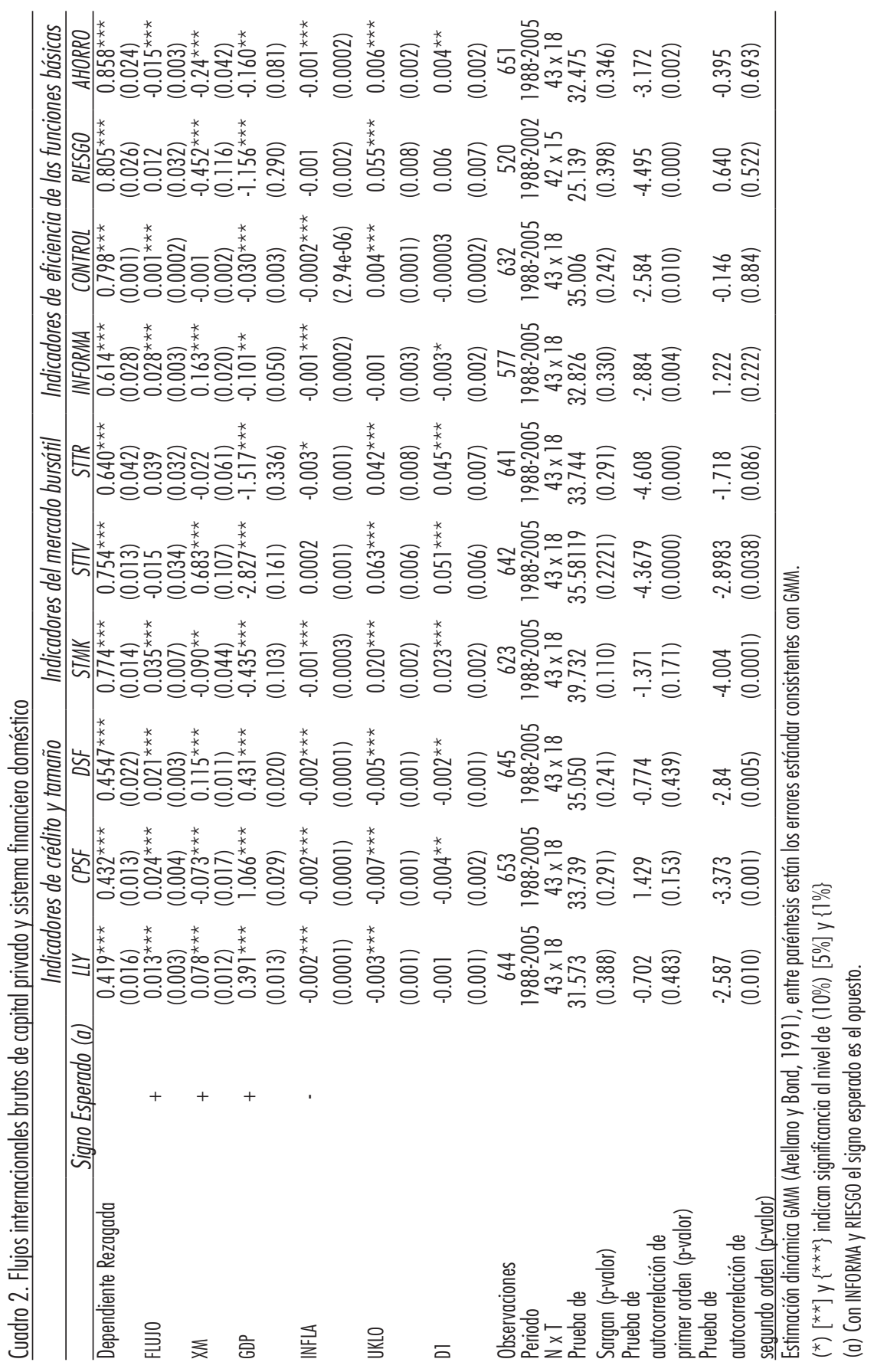


Edgar Tovar García

Un país desarrollado y con origen legal inglés se relaciona positiva y significativamente con el crecimiento del mercado bursátil. Se volvió a encontrar los mismos efectos en direcciones opuestas entre DI y GDP, y xM nuevamente se relaciona significativamente y con el signo contrario al esperado con los indicadores INFORMA (favorece la concentración bancaria) y AHORRO (perjudica la movilización y reunión del ahorro), y significativamente con el signo esperado con RIESGO (disminuye la volatilidad del consumo).

\section{Interdependencia financiera y sistema financiero doméstico}

Transformando al modelo [1] para usar como indicador de globalización financiera a la variable integración de la tasa de interés (INTERE) se obtiene el modelo [4].

$\ln D F_{i t}=\rho_{1} \ln D F_{i t-1}+\rho_{2} \ln I N T E R E_{i t-1}+\ln X_{i t-1}^{\prime} \beta+\gamma U K L O_{\mathrm{i}}+\lambda D 1_{\mathrm{i}}+u_{i t}$

En el Cuadro 3 se muestran los principales resultados, nótese que en este caso el signo esperado es negativo, porque entre menor sea la distancia de la tasa de interés del país $i$ con respecto a la tasa de interés de referencia, mayor es el grado de integración y de globalización financiera.

En su mayoría, los coeficientes de INTERE tienen el signo esperado y significancia estadística. No obstante, presenta coeficientes positivos y significativos al nivel de $1 \%$ con los indicadores LLY y DSF; por lo tanto, entre menos integrado esté un país mayor será el tamaño de su sistema financiero. Respecto al crecimiento del crédito ocurre lo opuesto, ya que la relación es negativa y significativa al nivel de $1 \%$ con CPSF.

Con los indicadores de crecimiento del mercado bursátil hay una relación inversa y significativa al nivel de $1 \%$ con STTV y STTR (con STMK no hay significancia estadística).

A mayor integración corresponde mayor eficiencia en el desempeño de dos funciones básicas del sistema financiero: control corporativo (CONTROL) y movilización y reunión de ahorro (AHORRO); las relaciones son significativas al nivel de $1 \%$ (no hay significancia estadística con las otras funciones del sistema financiero).

La apertura comercial, al igual que en los casos previos, tiene relaciones opuestas a las esperadas con los indicadores de eficiencia de las funciones básicas del sistema financiero. Favorece la concentración bancaria (INFORMA), perjudica el control corporativo (CONTROL) y afecta negativamente la movilización y reunión de ahorro (AHORRo). Aunque sí disminuye la volatilidad del consumo y por tanto, favorece la administración y diversificación del riesgo (RIESGO). 
Consecuencias de la globalización financiera sobre la eficiencia del sistema financiero

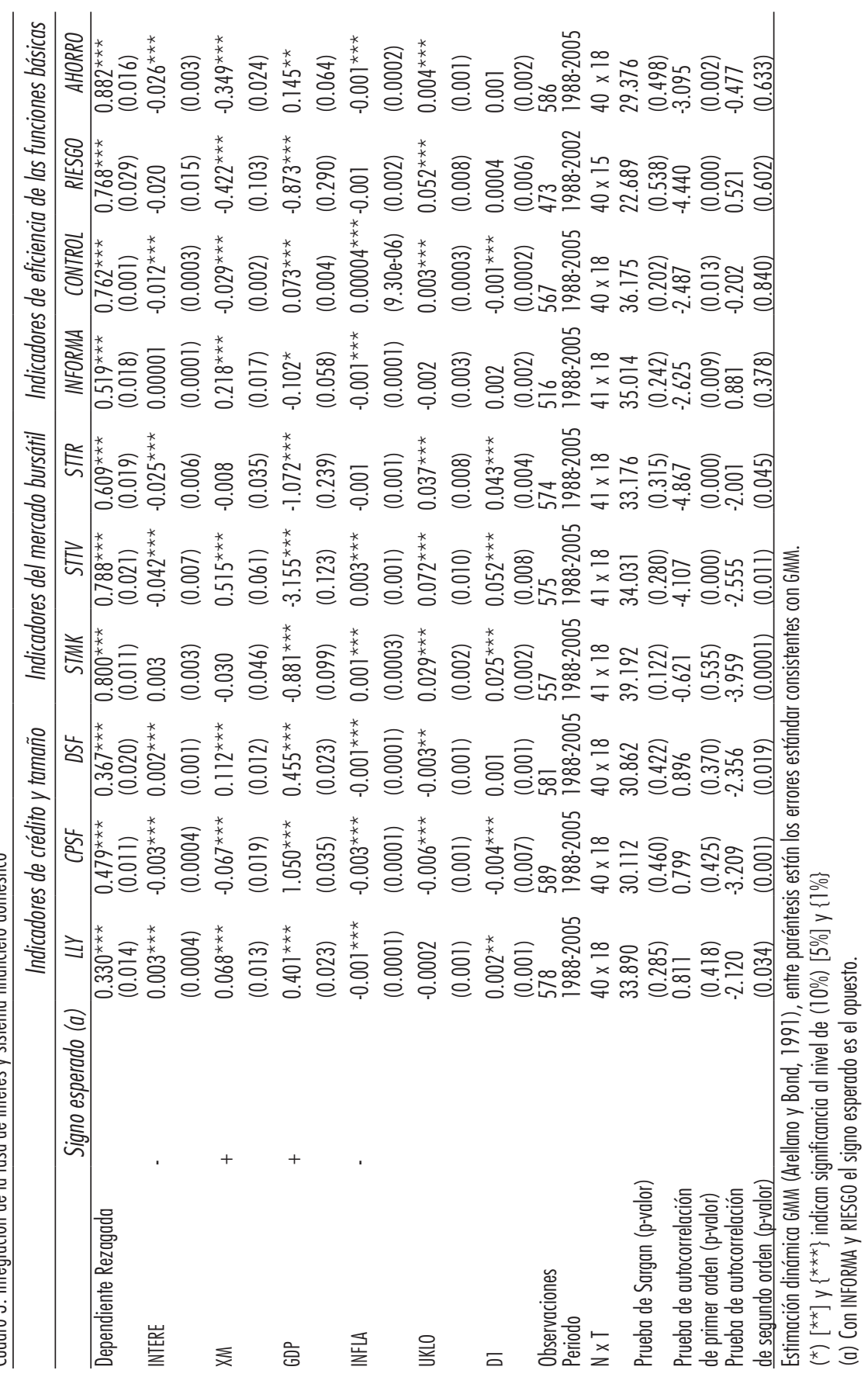


Edgar Tovar García

Se reiteran resultados encontrados en los otros dos modelos: efectos en direcciones opuestas por parte de DI y GDP; UKLO tiene efectos positivos sobre el control corporativo, la movilización y reunión de ahorro y la concentración bancaria; y un país desarrollado y con origen legal inglés tiene efectos positivos sobre el mercado bursátil.

Cabe señalar que la apertura comercial (xM) en los tres modelos, se relaciona significativamente y de manera inversa con el indicador RIESGO, es decir, disminuye la volatilidad del consumo y en consecuencia favorece la administración y diversificación del riesgo. En cambio, se relaciona significativamente pero con el signo contrario al esperado con las otras funciones básicas del sistema financiero, esto es evidencia en contra de la hipótesis de Rajan y Zingales (2003), quienes argumentan que tanto la apertura comercial como la financiera deben favorecer al desarrollo financiero.

\section{CONCLUSIONES}

Los sistemas financieros domésticos desempeñan sus funciones básicas con distintos niveles de eficiencia, pero gracias a la globalización financiera, que permite la interacción con los agentes financieros externos, es posible importar las mejores prácticas financieras a través de un proceso de catching up, y de este modo favorecer no sólo la profundización financiera sino también el desarrollo del sistema financiero nacional.

En esta investigación, con indicadores sobre el crecimiento del crédito y del mercado bursátil ampliamente utilizados en la literatura, se elaboraron pruebas empíricas que al igual que otros estudios, sugieren que la globalización financiera tiene efectos positivos sobre la profundización financiera aunque con matices, porque en especial un país desarrollado y con origen legal inglés tiene efectos positivos sobre el crecimiento del mercado bursátil.

Lo anterior no significa necesariamente que el sistema financiero desempeñe con mayor eficiencia sus funciones básicas, y por ello también se elaboraron pruebas con nuevos indicadores que permiten aproximar la eficiencia con la que un sistema financiero desempeña cuatro de sus funciones básicas.

Entre los resultados destaca que los tres indicadores de globalización financiera; apertura financiera (KAOPEN), flujos brutos de capital (FLUJO) e integración de la tasa de interés (INTERE), favorecen el control corporativo (CONTROL).

FLUJO se relaciona positivamente con la concentración bancaria (INFORMA), por lo tanto estos flujos no buscan la competencia sino la colusión, y perjudican la información sobre las condiciones de los mercados financieros. 
La globalización financiera tiene efectos mixtos sobre la función de movilizar y reunir ahorro, los indicadores KAOPEN e INTERE respaldan efectos positivos sobre la eficiencia de dicha función, pero FLUjo se relaciona negativamente por consiguiente, los flujos de capital pueden estar sustituyendo al ahorro doméstico.

KAOPEN es el único indicador de globalización financiera que tiene un efecto estadísticamente significativo sobre RIESGO; se advierte que a mayor apertura financiera le corresponde mayor volatilidad del consumo y consecuentemente perjudica la administración y diversificación del riesgo.

En general, puede señalarse que la globalización financiera favorece que los sistemas financieros domésticos tengan un mejor control y monitoreo sobre la asignación de los recursos, y una mayor movilización y reunión del ahorro. Pero ello va acompañado de volatilidad en el consumo y mayor concentración bancaria, es decir, perjuicios sobre la diversificación del riesgo y sobre la información de las condiciones de los mercados financieros.

Por consiguiente, la recomendación para los hacedores de política económica es mantener e incrementar el proceso de globalización financiera, pero debe vigilarse que los flujos de capital no consoliden estructuras oligopólicas, y prever que la administración y diversificación del riesgo no mejora sino que empeora con la apertura financiera. Tanto los flujos de capital como la política de apertura financiera deben ir acompañados de un proceso de integración de la tasa de interés; de lo contrario es de esperar efectos dañinos sobre el grado de eficiencia con que el sistema financiero doméstico desempeña sus funciones básicas.

\section{BIBLIOGRAFÍA}

Ang, James B., "Survey of Recent Developments in the Literature of Finance and Growth”, Journal of Economic Surveys, num. 22, 2008, pp. 536-576.

Arellano, Manuel y Stephen Bond, "Some Tests of Specification for Panel Data: Monte Carlo Evidence and an Application to Employment Equations", The Review of Economic Studies, num. 58, 1991, pp. 277-297.

Arestis, Philip, Machico Nissanke y Howard Stein, "Finance and Development: Institutional and Policy Alternatives to Financial Liberalization", Eastern Economic Journal, vol. 31, num. 2, 2005, pp. 245-263.

Bailliu, Jeannine N., "Private Capital Flows, Financial Development, and Economic Growth in Developing Countries", Working Paper num. 15, Bank of Canada, 2000. 
Edgar Tovar García

Baltagi, Badi H., Panicos O. Demetriades y Siong Hook Law, "Financial Development and Openness: Evidence from Panel Data", Journal of Development Economics, num. 89, 2009, pp. 285-296.

Beck, Thorsten, Asli Demirgüç-Kunt. y Ross Levine, "Financial Institutions and Markets Across Countries and over Time Data and Analysis", Policy Research Working Paper num. 4943, World Bank, 2009.

Bekaert, Geert, Campbell R. Harvey, y Christian Lundblad, "Growth Volatility and Equity Market Liberalization", Journal of International Money and Finance, num. 25, 2006, pp. 370-403.

, "Does Financial Liberalization Spur Growth?", Journal of Financial Economics, num. 77, 2005, pp. 3-56.

Boyd, John H., Ross Levine y Bruce D. Smith, "The Impact of Inflation on Financial Sector Performance", Journal of Monetary Economics, num. 47, 2001, pp. 221-248.

Calderón, Cécar y Megumi Kubota, "Does financial Openness Lead to Deeper Domestic Financial Markets?", Policy Research Working Paper Series num. 4973, World Bank, 2009.

Chinn, Menzie D. y Hiro Ito, "A New Measure of Financial Openness", Journal of Comparative Policy Analysis, vol. 10, num. 3, 2008, pp. 309-322.

, "What Matters for Financial Development? Capital Controls, Institutions and Interactions", Journal of Development Economics, num. 81, 2006, pp.163-192.

, "Capital Account Liberalization, Institutions and Financial Development: Cross Country Evidence”, National Bureau of Economic Research Working Paper, num. 8967, 2002.

De Gregorio, José, "Financial Integration, Financial Development and Economic Growth”, Estudios de Economía, vol. 26, núm. 2, 1999, pp. 137-61.

Do, Quy-Toan y Andrei A. Levchenko, "Trade and Financial Development", Policy Research Working Paper num. 3347, World Bank, 2004.

Edison, Hali J. y Francis E. Warnock, "A Simple Measure of the Intensity of Capital Controls", International Finance Discussion Paper num. 708, Washington, D.C., Board of Governors of the Federal Reserve System, September, 2001.

Edison, Hali J., Ross Levine, Luca Ricci y Torsten Slok "International Financial Integration and Economic Growth", National Bureau of Economic Research Working Paper num. 9164, 2002.

Edwards, Sebastian, "Capital Mobility and Economic Performance: Are Emerging Economies Different?", National Bureau of Economic Research Working Paper num. 8076, January, 2001. 
Eichengreen, Barry y David Leblang, "Capital Account Liberalization and Growth: Was Mr. Mahathir Right?”, National Bureau of Economic Research Working Paper num. 9427, 2003.

Fischer, Stanley, "Globalization and its Challenges", American Economic Review, vol. 93, num. 2, 2003, pp. 1-30.

Huang, Wei, "Emerging Markets Financial Openness and Financial Development", Discussion Paper num. 06/588. Department of Accounting and Finance, University of Bristol, 2006.

Huang, Yongfu, "What Determines Financial Development?", University of Bristol, Discussion Paper num. 05/580, 2005.

Huang, Yongfu y Jonathan Temple, "Do External Trade Promote Financial Development?" Bristol Economics Discussion Paper num. 05/575. Department of Economics, University of Bristol, Bristol, 2005.

Klein, Michael y Giovanni Oliver, "Capital Account Liberalization, Financial Depth and Economic Growth", National Bureau of Economic Research Working Paper num.7384, 2001.

Kose, M. Ayhan, Eswar S. Prasad y Marco E. Terrones, "How Does Financial Globalization Affect Risk Sharing? Patterns and Channels", IZA Discussion Paper num. 2903, 2007.

Lane, Philip R. y Gian Maria Milesi-Ferretti, "The External Wealth of Nations Mark II: Revised and Extended Estimates of Foreign Assets and Liabilities, 1970-2004", International Monetary Fund Working Paper 06/69, Washington, International Monetary Fund, 2006.

La Porta, R., F. Lopez-de-Silanes, A. Shleifer y R. W. Vishny, "Law and Finance", Journal of Political Economy, vol. 106, num. 6, 1998, pp. $1113-1155$.

Law, Siong Hook, "Trade Openness, Capital Flows and Financial Development in Developing Economies", International Economic Journal, vol. 23, num. 3, 2009, pp. 409-426.

Law, Siong Hook y Panicos Demetriades, "Openness, Institutions and Financial Development”, World Economy \& Finance Research Programme, Working Paper Wef 0012, 2006.

Levine, Ross, "Finance and Growth: Theory and Evidence" en Aghion P. y Durlauf S. (eds.), Handbook of Economic Growth, Amsterdam, NorthHolland Elsevier Publishers, 2005.

, "Bank-based or Market-based Financial Systems: Which is Better?", Journal of Financial Intermediation, num. 11, 2002, pp. 398-428.

, "Financial Development and Economic Growth: Views and Agenda”, Journal of Economic Literature, num. 35, 1997, pp. 688-726. 
Levine, Ross y Sara Zervos, "Capital Control Liberalization and Stock Market Development," World Development, num. 26, 1998, pp. 1169-1184.

Levy, Noemi, "The Effects of External Capital Flows on Developing Countries Financial Instability or "Wrong" Prices?", International Journal of Political Economy, vol. 37, num. 4, 2009, pp. 80-102.

Lindgren, Carl-Johan, Gillan Garcia, y Matthew I. Saal, Banking Soundness and Macroeconomic Policy, Washington, DC, International Monetary Fund, 1996.

McKinnon, Ronald I., Money and Capital in Economic Development. Washington, D.C., Brookings Institution, 1973.

Morck Randall K. y Lloyd Steier, "The Global History of Corporate Governance an Introduction" National Bureau of Economic Research Working Paper num. 11062, 2005.

Naceur, Samy Ben, Samir Ghazouani y Mohammed Omran, "Does Stock Market Liberalization Spur Financial and Economic Development in the MENA region?", Journal of Comparative Economics, num. 36, 2008, pp. 673-693.

Obstfeld, Maurice, "International Finance and Growth in Developing Countries: What Have We Learned?", World Bank Working Paper num. 34, Washington, DC, Commission on Growth and Development, World Bank, 2008. , "The Global Capital Market: Benefactor or Menace?", The Journal of Economic Perspectives, vol. 12, num. 4, 1998, pp. 9-30. , "Risk-Taking, Global Diversification, and Growth", American Economic Review, num. 84, 1994, pp. 1310-1329.

Obstfeld, Maurice y Alan M., Taylor, "Globalization and Capital Markets". en Bordo, M. D., Taylor, A. y J. G. Williamson, (eds.), Globalization in Historical Perspective, Cambridge, Ma: National Bureau of Economic Research, 2003, pp. 121-188.

Prasad, Eswar, Raghuram G. Rajan, y Arvind Subramanian, "Foreign Capital and Economic Growth", Brookings Papers on Economic Activity, num. 1, 2007, pp. 153-230.

Prasad, E., Kenneth Rogoff, Shang-Jin Wei y M. Ayhan Kose, "Effects of Financial Globalization on Developing Countries: Some Empirical Evidence", International Monetary Fund Occasional Paper num. 220, Washington, International Monetary Fund, 2003.

Rajan, Raghuram G. y Luigi Zingales, "The Great Reversals: the Politics of Financial Development in the Twentieth Century", Journal of Financial Economics, num. 69, 2003, pp. 5-50.

Roubini, Nouriel y Xavier Sala-I-Marti, "A Growth Model of Inflation, Tax Evasion, and Financial Repression", Journal of Monetary Economics, num. 35, 1995, pp. 275-301. 
Shaw, Edward S., Financial Deepening in Economic Development, New York, Oxford University Press, 1973.

Shleifer, Andrei y Robert W. Vishny, "Large Shareholders and Corporate Control”, Journal of Political Economy, num. 94, 1986, pp. 461-488.

Stiglitz, Joseph E., "Capital Market Liberalization, Economic Growth and Instability”, World Development, vol. 28, num. 6, 2000, pp. 1075-86.

\section{ANEXO}

Cuadro A. Resumen estadístico. Variables de desarrollo financiero, globalización financiera y de control

\begin{tabular}{|c|c|c|c|c|c|c|c|}
\hline Variable & Fuente & Unidad de medida & Observaciones & Media & $\begin{array}{c}\text { Desviación } \\
\text { estándar }\end{array}$ & Mínimo & Máximo \\
\hline LLY & Beck et al. (2009) & Proporción al PIB & 757 & 0.65 & 0.36 & 0.12 & 2.42 \\
\hline CPSF & Beck et al. (2009) & Proporción al PIB & 764 & 0.73 & 0.45 & 0.08 & 2.01 \\
\hline DSF & Beck et al. (2009) & Proporción al PIB & 760 & 0.61 & 0.35 & 0.08 & 2.30 \\
\hline STMK & Beck et al. (2009) & Proporción al PIB & 729 & 0.55 & 0.52 & 0.002 & 3.03 \\
\hline STTV & Beck et al. (2009) & Proporción al PIB & 751 & 0.35 & 0.48 & 0.00004 & 3.26 \\
\hline STTR & Beck et al. (2009) & Proporción al PIB & 749 & 0.54 & 0.60 & 0.004 & 6.22 \\
\hline INFORMA & Beck et al. (2009) & Razón simple & 682 & 0.67 & 0.20 & 0.20 & 1.00 \\
\hline CONTROL & Beck et al. (2009) & Razón simple & 739 & 0.90 & 0.13 & 0.31 & 1.00 \\
\hline RIESGO & $\begin{array}{l}\text { Elaboración propia } \\
\text { con datos de WDI }\end{array}$ & Razón simple & 610 & 1.17 & 0.97 & 0.15 & 6.43 \\
\hline AHORRO & Beck et al. (2009) & Razón simple & 768 & 1.06 & 0.38 & 0.30 & 3.05 \\
\hline KAOPEN & Chinn e Ito (2008) & $\begin{array}{l}\text { Componente principal } \\
\text { (índice) }\end{array}$ & 766 & 1.05 & 1.53 & -1.81 & 2.53 \\
\hline FLUJO & WDI & Porcentaje de PIB & 771 & 22.99 & 34.01 & 0.81 & 355.56 \\
\hline INTERE & $\begin{array}{l}\text { Elaboración propia } \\
\text { con datos de WDI }\end{array}$ & Porcentaje & 696 & 4.72 & 7.68 & 0.03 & 80.38 \\
\hline XM & WDI & Porcentaje de PIB & 754 & 69.70 & 44.62 & 13.74 & 456.09 \\
\hline GDP & WDI & $\begin{array}{l}\text { Per cápita, dólares } \\
\text { Constantes }\end{array}$ & 774 & 12849 & 11047 & 297 & 40595 \\
\hline INFLA & WDI & Porcentaje & 770 & 9.85 & 16.42 & -0.90 & 114.16 \\
\hline
\end{tabular}

Países desarrollados: Alemania (GELO), Australia (UKLO), Austria (GELO), Bélgica (FRLO), Canadá (UKLO), Dinamarca (SCLO), España (FRLO), Estados Unidos (UKLO), Finlandia (SCLO), Francia (FRLO), Grecia (FRLO), Irlanda (UKLO), Italia (FRLO), Japón (GELO), Noruega (SCLO), Nueva Zelanda (UKLO), Países Bajos (FRLO), Portugal (FRLO), Reino Unido (UKLO), Suecia (SCLO), Suiza (GELO). Países en vías de desarrollo: Colombia (FRLO), Corea (GELO), Chile (FRLO), Ecuador (FRLO), Egipto (FRLO), Filipinas (FRLO), India (UKLO), Indonesia (FRLO), Israel (UKLO), Jordania (FRLO), Kenya (UKLO), Malasia (UKLO), México (FRLO), Nigeria (UKLO), Pakistán (UKLO), Singapur (UKLO), Sri Lanka (UKLO), Sudáfrica (UKLO), Tailandia (UKLO), Turquía (FRLO), Uruguay (FRLO), Venezuela (FRLO).

UKLO: Origen de la legislación comercial inglés, FRLO: Origen de la legislación comercial francés, SCLO: Origen de la legislación comercial escandinavo, GELO: Origen de la legislación comercial alemán. 
Edgar Tovar García

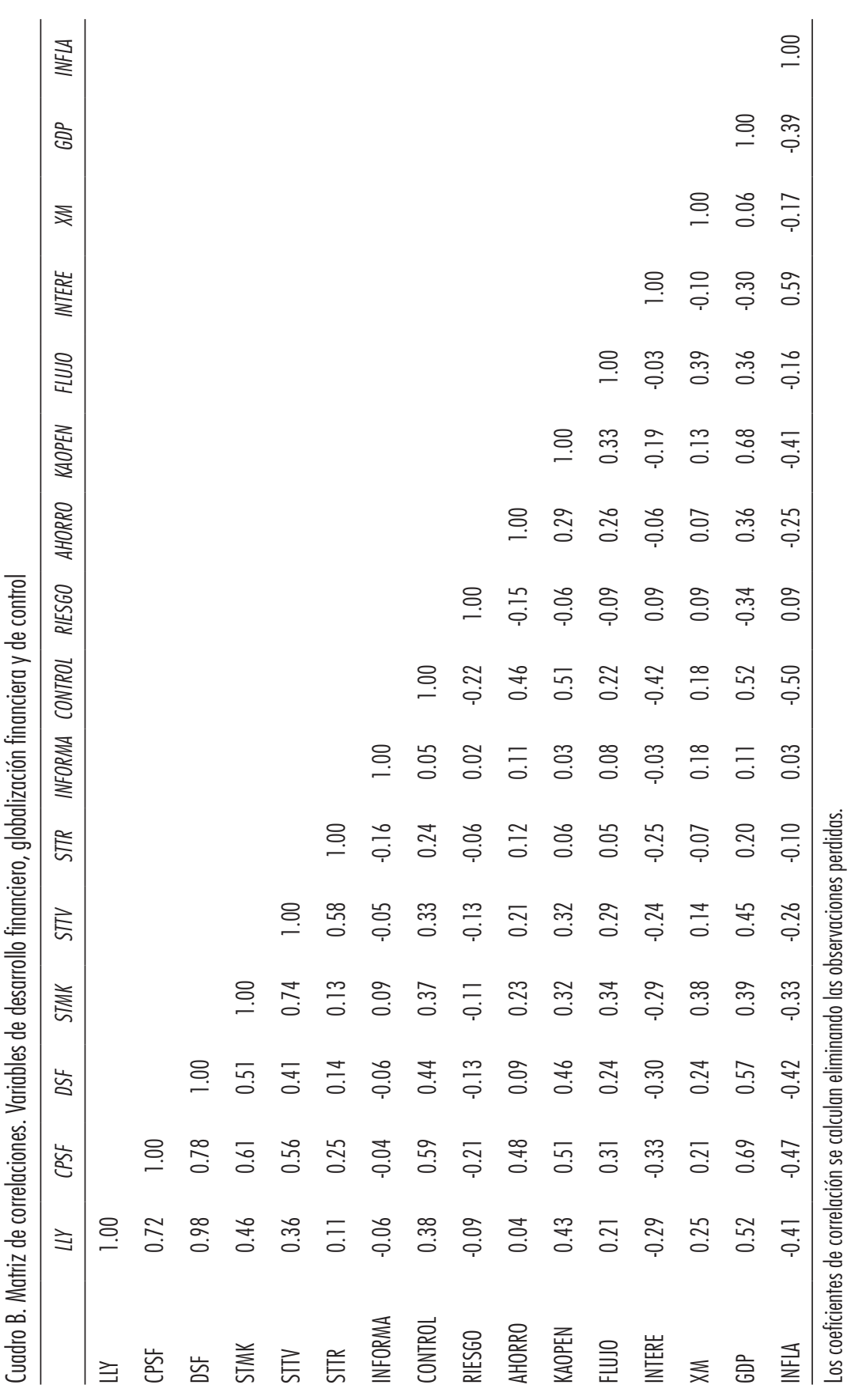

